Check for updates

Cite this: RSC Adv., 2019, 9, 9937

\title{
Formation mechanism of nanoporous silver during dealloying with ultrasonic irradiation
}

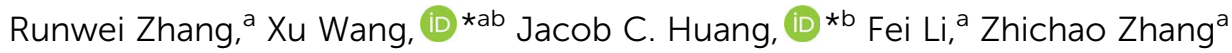 \\ and Ming $\mathrm{Wu}^{\mathrm{a}}$
}

Nanoporous silver (NPS) with an extreme coarsened 3-dimensional bi-continuous ligament and nanopore structure could be prepared by chemical dealloying with high-intensity ultrasonic irradiation (UI). The formation mechanism of NPS dealloying with UI was different from NPS obtained through free corrosion. It evolved into NPS with a new lump forming-disintegrating mechanism. Ultrasonic irradiation had strong effects on the dealloying process of NPS. The stirring effect produced by ultrasonic vibration could promote the corrosion of $\mathrm{Cu}$ and facilitate the diffusion of $\mathrm{Ag}$ atoms. Therefore, the coarsening rate of the ligament was increased significantly. Dealloying assisted by UI could generate an extremely coarsened microstructure of which ligament and pore sizes were much larger than those obtained from free corrosion dealloying.

Received 7th March 2019

Accepted 25th March 2019

DOI: 10.1039/c9ra01742a

rsc.li/rsc-advances nature of the precursor alloy, composition of the precursor alloy, dealloying time, dealloying temperature, and dealloying solution. ${ }^{\mathbf{1 4 - 1 7}}$ A slight change in modulation of these factors may lead to a remarkable difference in the microstructure of nanoporous metals. Based on this effect, an efficient dealloying process and a tunable nanoporous structure were presented. ${ }^{\mathbf{1 8 - 2 0}}$

However, the dealloying process can be more efficient and the microstructure will be more desirable when the dealloying process is carried out with the assistant treatments. ${ }^{16,21}$ Nanoporous $\mathrm{Ag}$ micro-particles have been prepared by ultrasonic assisted dealloying $\mathrm{Mg}-\mathrm{Ag}$ alloy. ${ }^{22}$ The length scale of the ligament is not only sensitive to the concentration of the dealloying solution but also to the intensity of ultrasonic irradiation. The influence of a magnetic field on the dealloying of $\mathrm{Al}-25 \mathrm{Ag}$ has also been elucidated. ${ }^{23}$ According to the experimental results, an external magnetic field accelerates the dealloying process and the microstructure obtained from dealloying with magnetic treatment is more homogeneous than those from free corrosion dealloying. Moreover, the nanoporous $\mathrm{Ag}$ foam was fabricated by dealloying Ag-Al thin film through supercritical fluid corrosion. ${ }^{4}$ Recently, a three-dimensional bicontinuous nanoporous materials could be obtained by vapor phase dealloying. ${ }^{24}$

As we all know, ultrasonic vibration has been widely applied for purification, degassing, refining metallic melts and fabricating particulate-reinforced metal matrix composites. ${ }^{25-28}$ In the present work, the nanoporous Ag with an extreme coarsened microstructure is obtained by chemical dealloying with ultrasonic irradiation at different frequencies. Therefore, a time saving method for preparing nanoporous Ag was presented and a lower acid concentration was acquired to obtain NPS. It could avoid time consuming and reduce environment pollution simultaneously. Not only the surface diffusion during 


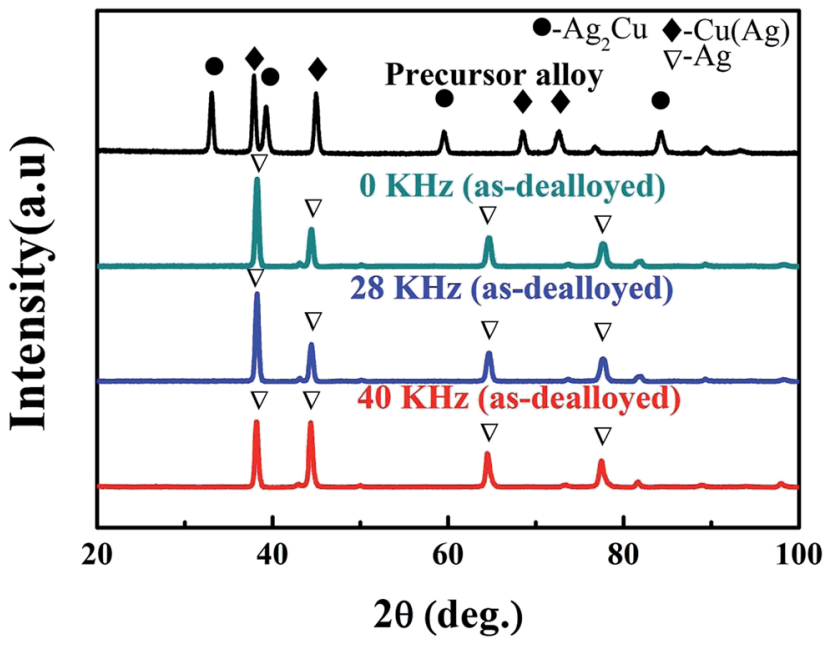

Fig. 1 XRD results of $\mathrm{Ag}_{25} \mathrm{Cu}_{75}$ precursor alloy and ribbons dealloyed without or with $\mathrm{UI}$ at different frequencies $(28,40 \mathrm{KHz})$ for $20 \mathrm{~min}$.

dealloying process with ultrasonic irradiation (UI) is studied, but also the effect of UI on the resulting nanoporous structure is discussed. Extremely large variations between the microstructure of the nanoporous Ag dealloyed under free corrosion and nanoporous Ag dealloyed with UI are observed. In addition, different UI frequencies would have different effects on the dealloying process and diffusion of Ag atoms. Therefore, the relationship between the nanoporous $\mathrm{Ag}$ ligament and other dealloying parameters is elucidated. A new formation mechanism of nanoporous $\mathrm{Ag}$ is also presented.

\section{Experiment}

$\mathrm{Ag}-\mathrm{Cu}$ alloy with the nominal composition of $\mathrm{Ag}_{25} \mathrm{Cu}_{75}$ (at\%) was prepared by melting pure $\mathrm{Ag}(99.95 \mathrm{wt} \%)$ and pure $\mathrm{Cu}$ (99.95 wt\%) in a graphite crucible using a high-frequency induction furnace under an argon atmosphere. The prealloyed $\mathrm{Ag}-\mathrm{Cu}$ alloy ingots were re-melted in a highly pure argon atmosphere and were subsequently injected onto a copper roller (cooling rate: $50-300{ }^{\circ} \mathrm{C} \mathrm{s}^{-1}$; rotational speed: $2500 \mathrm{rpm}$ ). The ingots were then rapidly solidified into ribbons, which are normally $40-60 \mu \mathrm{m}$ thick, $10-15 \mathrm{~mm}$ wide and several centimeters long.

Dealloying of the samples was then performed at $45^{\circ} \mathrm{C}$ under different conditions: (1) under free corrosion in a $10 \mathrm{wt} \% \mathrm{HNO}_{3}$ aqueous solution for 5,10 and $20 \mathrm{~min}$; (2) with UI at the constant frequency of $28 \mathrm{kHz}$ in a $10 \mathrm{wt} \% \mathrm{HNO}_{3}$ aqueous solution for 5, 10 and $20 \mathrm{~min}$; and (3) with UI at the frequency of $40 \mathrm{kHz}$ in a $10 \mathrm{wt} \% \mathrm{HNO}_{3}$ aqueous solution for 5,10 and $20 \mathrm{~min}$. The dealloyed samples were then rinsed three or four times sequentially using alcohol and distilled water. Under the effect of UI, the temperature of dealloying system would increase $1-2{ }^{\circ} \mathrm{C}$.

Phase patterns of the $\mathrm{Ag}-\mathrm{Cu}$ precursor alloys and dealloyed samples were analyzed by X-ray diffraction (XRD, MAXima7000) using $\mathrm{Cu} \mathrm{K} \alpha$ radiation with a scanning speed of

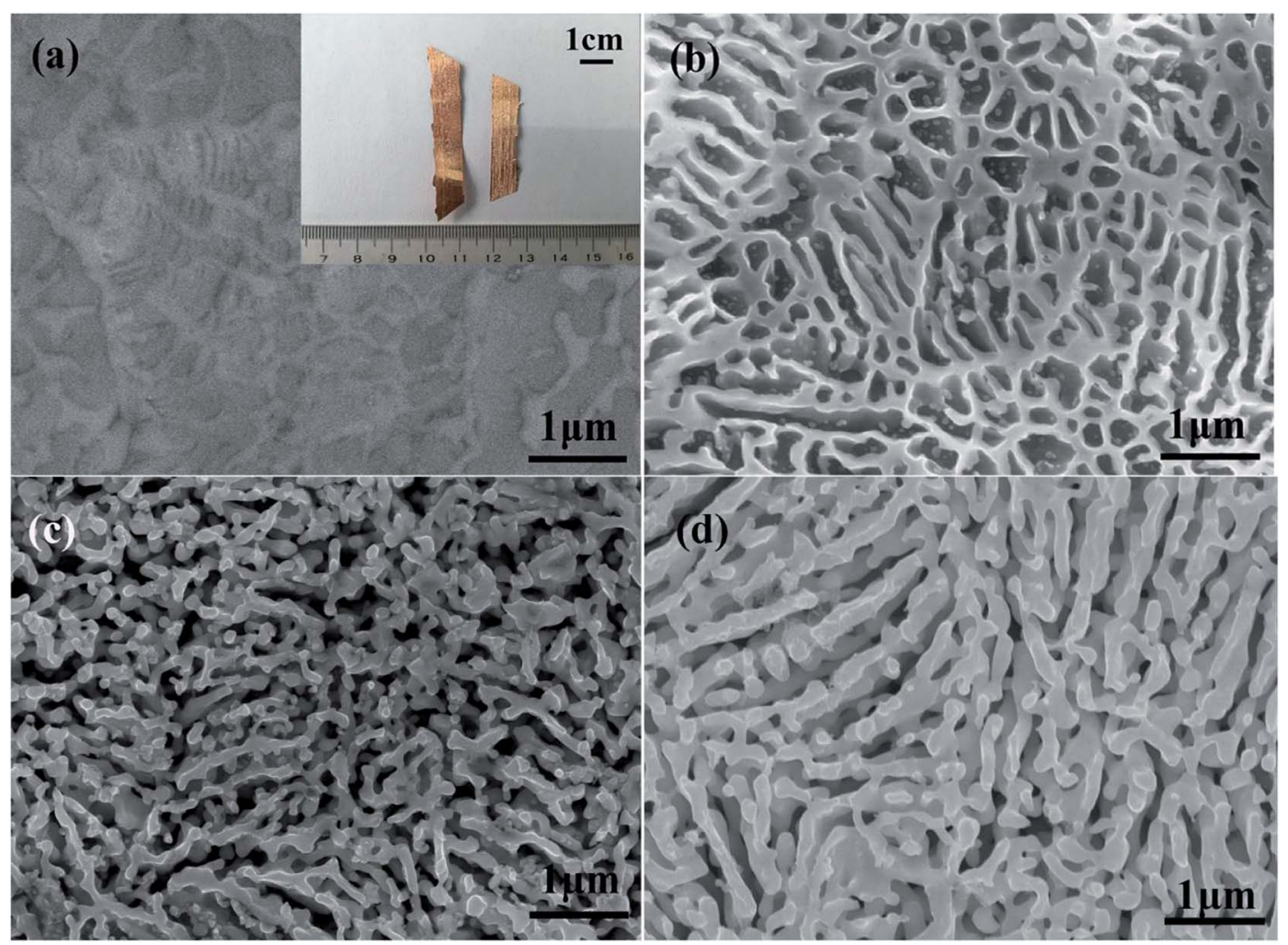

Fig. 2 SEM images of the $\mathrm{Ag}_{25} \mathrm{Cu}_{75}$ samples (plan view) dealloyed without UI for different periods of time: (a) $0 \mathrm{~min}$, (b) 5 min, (c) $10 \mathrm{~min}$, and (d) 20 min. The inset of (a) is the photograph of $\mathrm{Ag}_{25} \mathrm{Cu}_{75}$ initial alloy. 
$2^{\circ} \min ^{-1}$. The $2 \theta$ scans were performed between $20^{\circ}$ and $90^{\circ}$. Microstructures and elemental content of the $\mathrm{Ag}-\mathrm{Cu}$ precursor alloys and the dealloyed samples were characterized by transmission electron microscopy (TEM, JEOL-2100F) and scanning electron microscopy (SEM, Hitachi SU8000) equipped with an energy dispersive X-ray spectrometer (EDS, BRUKER). The ligament or pore sizes of nanoporous Ag in SEM images were measured by an image processing software ImageJ.

\section{Results and discussion}

\section{Microstructure characterization and phase composition}

The XRD results of the $\mathrm{Ag}_{25} \mathrm{Cu}_{75}$ alloy dealloyed in a $10 \mathrm{wt} \%$ $\mathrm{HNO}_{3}$ solution at $45{ }^{\circ} \mathrm{C}$ without UI and with ultrasonic irradiation at different frequencies are presented. The XRD patterns of $\mathrm{Ag}_{25} \mathrm{Cu}_{75}$ initial alloy sample was shown in Fig. 1 and the photograph of $\mathrm{Ag}_{25} \mathrm{Cu}_{75}$ initial alloy was inset in Fig. 2a. It can be seen that two phases were present in the initial alloy: $\alpha$ $\mathrm{Cu}(\mathrm{Ag})$ solid solution and an $\mathrm{Ag}_{2} \mathrm{Cu}$ intermetallic compound. This result was close to those presented previously. ${ }^{7}$ As shown in Fig. 1, only a single Ag phase was left in the samples after dealloying for 20 min without UI and with UI at the frequencies of 28 and $40 \mathrm{kHz}$ respectively. It is obvious that $\mathrm{Cu}$ from the $\mathrm{Ag}_{25} \mathrm{Cu}_{75}$ initial alloy was etched away during the dealloying process and all samples were dealloyed thoroughly after $20 \mathrm{~min}$. In fact, the dealloying speed of $\mathrm{Ag}_{25} \mathrm{Cu}_{75}$ alloy was faster when dealloyed with UI than free corrosion. Technically, there was always a small amount of residual $\mathrm{Cu}$ existing in the final NPS. So it was not taken into account since the content of residual $\mathrm{Cu}$ was too little. ${ }^{19}$

The evolution of alloy microstructure during the dealloying process without UI was characterized. Fig. 2 shows the SEM images of the NPS ribbons (plan view) dealloyed from the $\mathrm{Ag}_{25} \mathrm{Cu}_{75}$ alloys for different durations in a $10 \mathrm{wt} \% \mathrm{HNO}_{3}$

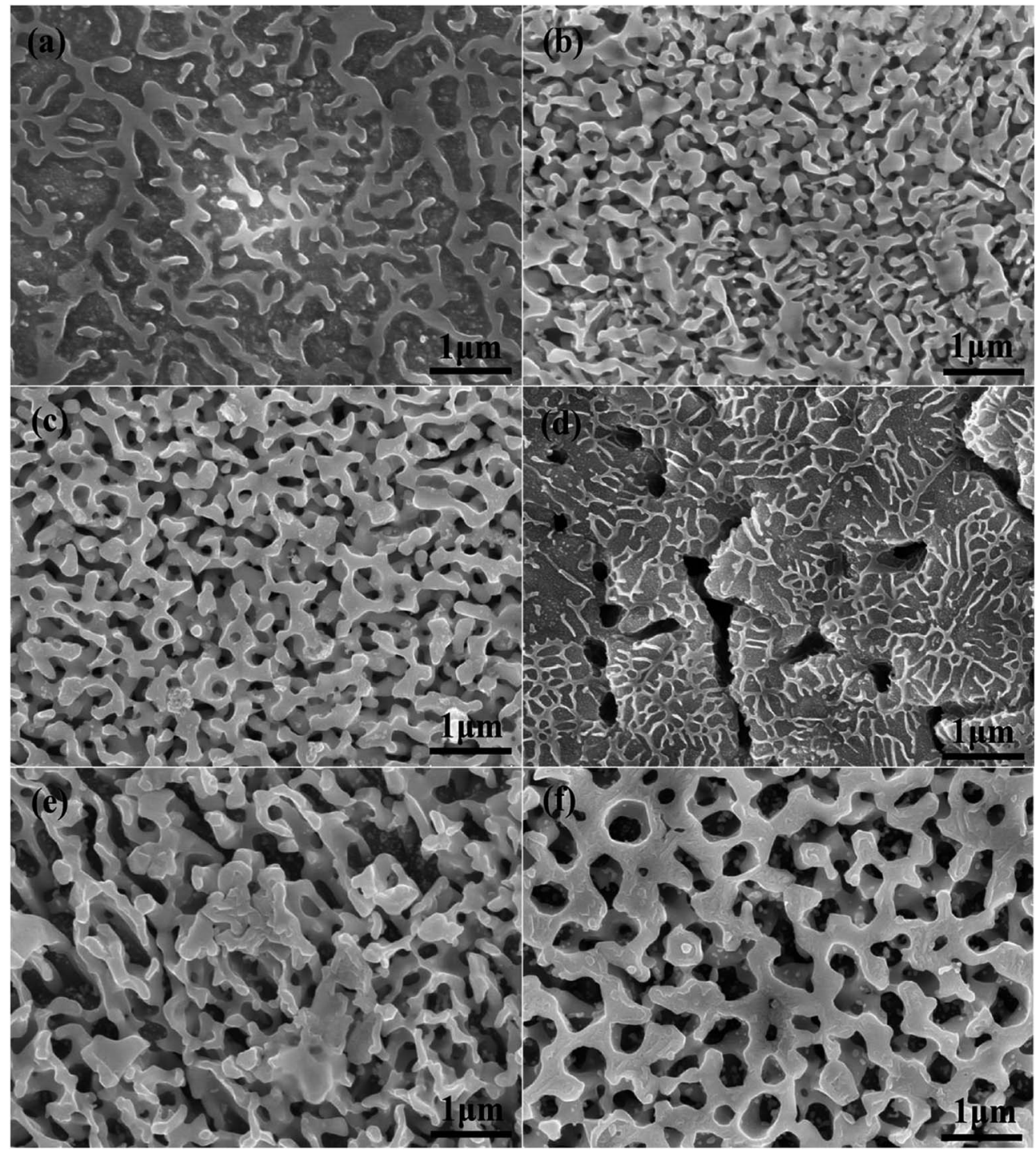

Fig. 3 (a-c) SEM images of the $\mathrm{Ag}_{25} \mathrm{Cu}_{75}$ samples (plan view) dealloyed with UI (frequency: $28 \mathrm{kHz}$ ) for different periods of time: (a) 5 min, (b) $10 \mathrm{~min}$, and (c) $20 \mathrm{~min}$. (d-f) SEM images of the $\mathrm{Ag}_{25} \mathrm{Cu}_{75}$ samples (plan view) dealloyed with UI (frequency: $40 \mathrm{kHz}$ ) for different periods of time: (a) $5 \mathrm{~min}$, (b) $10 \mathrm{~min}$, and (c) $20 \mathrm{~min}$. 

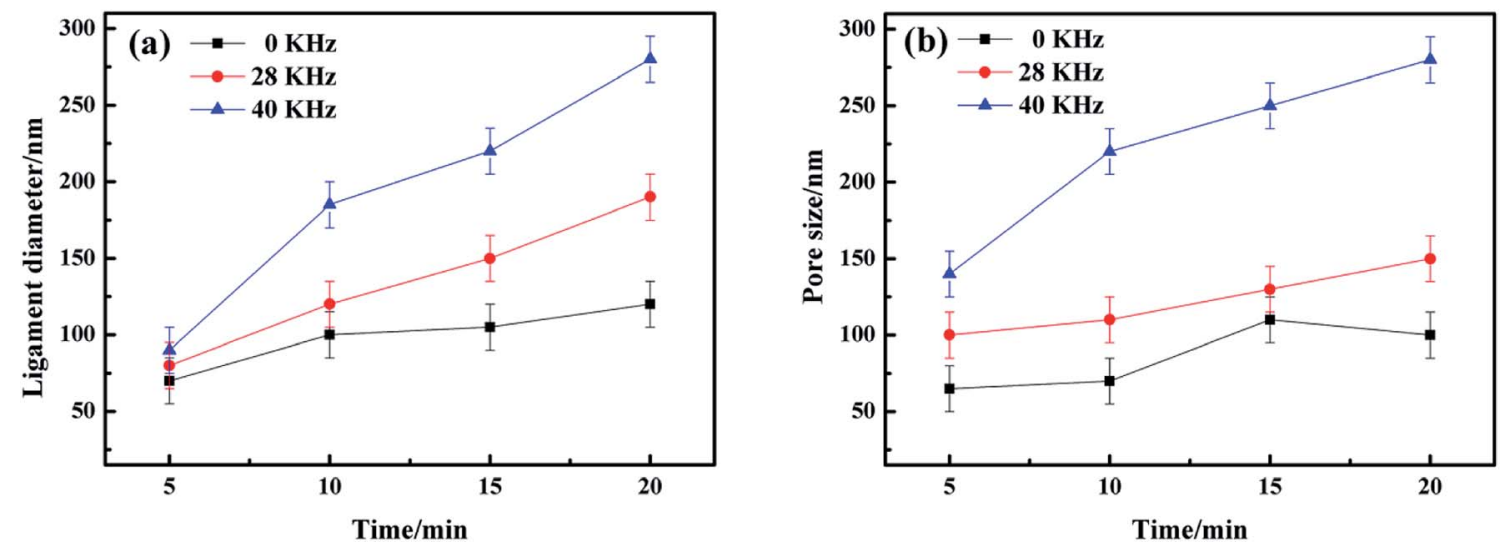

Fig. 4 (a) Ligament diameters and (b) pore sizes of $\mathrm{Ag}_{25} \mathrm{Cu}_{75}$ at different dealloying time under $\mathrm{UI}$ at frequencies of 0,28 and $40 \mathrm{kHz}$.

solution at $45^{\circ} \mathrm{C}$. The morphology of the resulting NPS ribbon exhibited a homogeneous, ligament-channel structure. After dealloying for $20 \mathrm{~min}$, the diameter of the ligament increased, and the size changed from $70 \pm 15$ to $120 \pm 15 \mathrm{~nm}$.

The SEM images of the NPS ribbons (plan view) dealloyed under UI (frequency: $28 \mathrm{kHz}$ ) for different durations are shown in Fig. 3a-c. The final microstructure was much coarsened than that of the $\mathrm{Ag}_{25} \mathrm{Al}_{75}$ alloy ribbon which was dealloyed without UI treatment. After dealloying for $20 \mathrm{~min}$, the diameter of the ligament increased from $80 \pm 15$ to $190 \pm 15 \mathrm{~nm}$. Fig. $3 \mathrm{~d}-\mathrm{f}$ show the SEM images of the NPS ribbons (plan view) dealloyed with UI (frequency: $40 \mathrm{kHz}$ ) for different durations. Many large cracks appeared on the alloy surface (Fig. 3d) which suggested that the high intensity of ultra-sonication gives rise to the cracks even fracture during the dealloying process. The as-dealloyed sample exhibited an microstructure with coarsened ligaments and enlarged pores. Moreover, the diameter of the ligament prepared from the $\mathrm{Ag}_{25} \mathrm{Al}_{75}$ alloy dealloyed for 20 min reached approximately $280 \mathrm{~nm}$ and was much larger than those of the $\mathrm{Ag}_{25} \mathrm{Al}_{75}$ alloys dealloyed with UI at the frequency of 0 or $28 \mathrm{kHz}$.
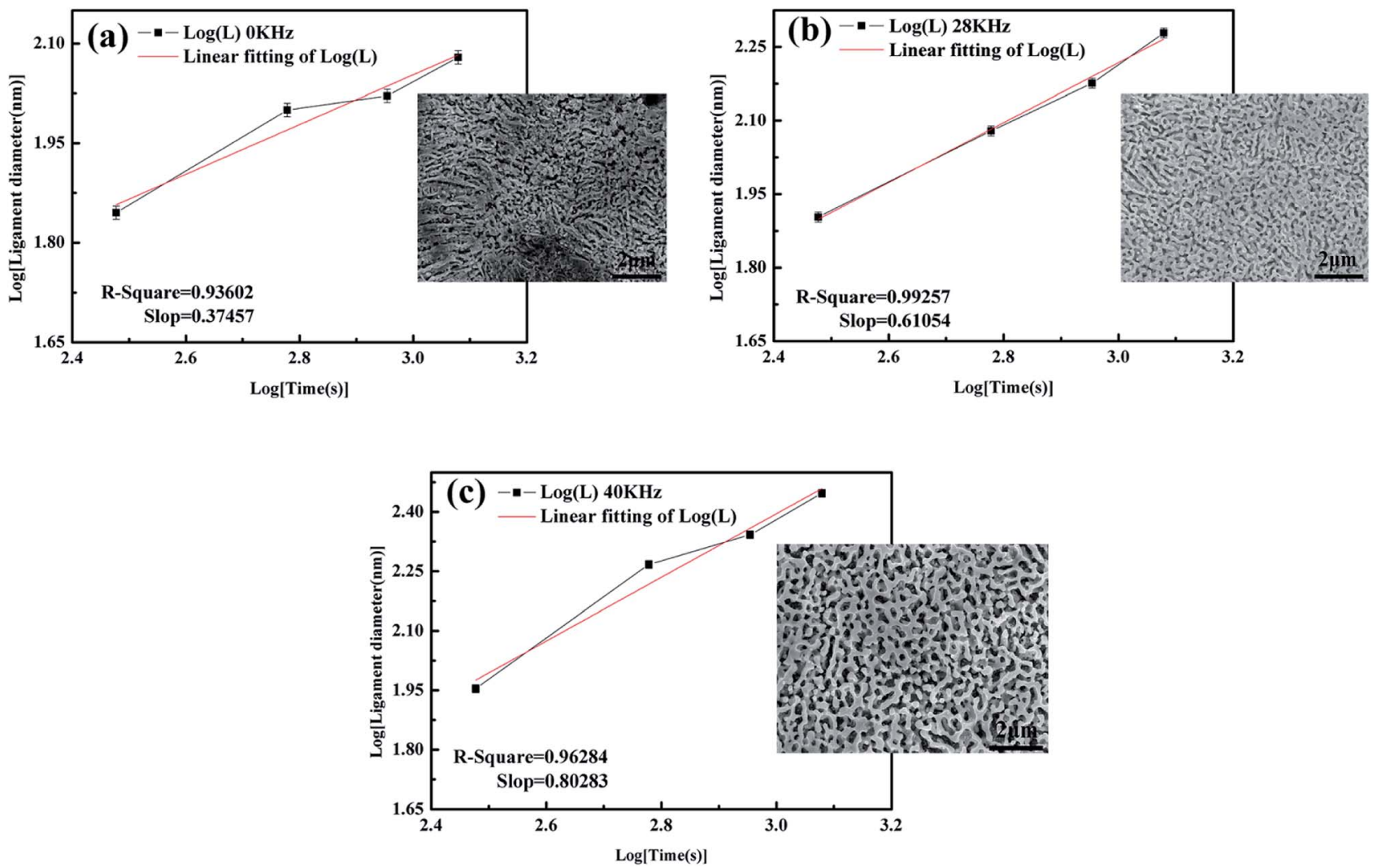

Fig. 5 The time dependence of the coarsening of ligament size at the frequencies of (a) 0 , (b) 28 and (c) 40 kHz respectively; Microstructure of NPS dealloyed under $\mathrm{UI}$ at the frequencies of 0,28 and $40 \mathrm{kHz}$ inset in (a), (b) and (c), respectively. 


\section{Effect of ultrasonic irradiation on microstructure of NPS}

The alterations of average ligament diameters and pore sizes with UI at different frequencies were measured and the data was shown in Fig. 4. It can be easily obtained that both ligament diameters and pore sizes increased with increasing dealloying time. And the final results of ligament and pore size were much larger than many of those from other researches. ${ }^{\mathbf{1 0 , 2 3 , 2 9}}$ The ligament diameters increased sharply for dealloying with UI, compared with those from free corrosion. Therefore, we concluded that a high-intensity ultrasonic irradiation would affect the microstructure of NPS remarkably.

Additionally, the coarsening of the ligament was caused by the diffusion of the more noble elements atoms which were driven by surface tension existing at the interface between the alloy and solution. ${ }^{30,31}$ With the reduction in the surface energy, the ligament coarsened gradually. ${ }^{32}$ It is well known that the coarsening mechanism of the ligament is controlled by the surface diffusivity $\left(D_{\mathrm{s}}\right)$ of the more noble elements: ${ }^{16}$

$$
D_{\mathrm{s}}=\frac{d(t)^{4} k T}{32 \gamma t a^{4}},
$$

where $k$ is Boltzmann constant, $T$ is the etching temperature, $\gamma$ is surface energy, $t$ is the etching time, and $a$ is the lattice parameter. Moreover, the relationship of $D_{\mathrm{s}}$ (surface diffusion of gold atoms) and $d$ (ligament diameter of nanoporous gold) when preparing nanoporous gold dealloyed from $\mathrm{Au}-\mathrm{Ag}$ alloy could be estimated by the following proposed equation: ${ }^{33}$

$$
d \propto\left(D_{\mathrm{s}} / V_{0}\right)^{\mu},
$$

where $V_{0}$ is the velocity of a flat alloy surface with no gold accumulated on it and $\mu$ is a constant equal to $1 / 6$ or $1 / 4$ depending on whether the theoretical or the empirical model is used. ${ }^{\mathbf{1 6}, 34}$ Hence, the coarsening rate of the ligament in this study may largely reflect the diffusion rate of $\mathrm{Ag}$ atoms. The time dependence of the ligament coarsening with UI at different frequencies can be observed in Fig. 5a-c. According to these plots, the relationship between time and ligament could be described as:

$$
\begin{aligned}
& d_{0 \mathrm{kHz}} \propto t^{0.37} \approx t^{2 / 5}, \\
& d_{28 \mathrm{kHz}} \propto t^{0.61} \approx t^{3 / 5}, \\
& d_{40 \mathrm{kHz}} \propto t^{0.80} \approx t^{4 / 5},
\end{aligned}
$$

where $d$ is the ligament size of NPS and $t$ is the dealloying duration. The exponents $(3 / 5$ and $4 / 5)$ were much larger than the reported surface diffusion exponents of $2 / 5$ for NPS and $1 / 8$ for nanoporous Au. ${ }^{35,36}$ It is now demonstrated that the coarsening rate of the ligament would be increased through dealloying with UI. The morphology of NPS dealloyed with UI was observed to be much more coarsened than that of the NPS dealloyed without the ultrasonic treatment through the analysis of the SEM results inset in Fig. 5a, b and c, respectively. This is well consistent with the result that the ligament diameter and

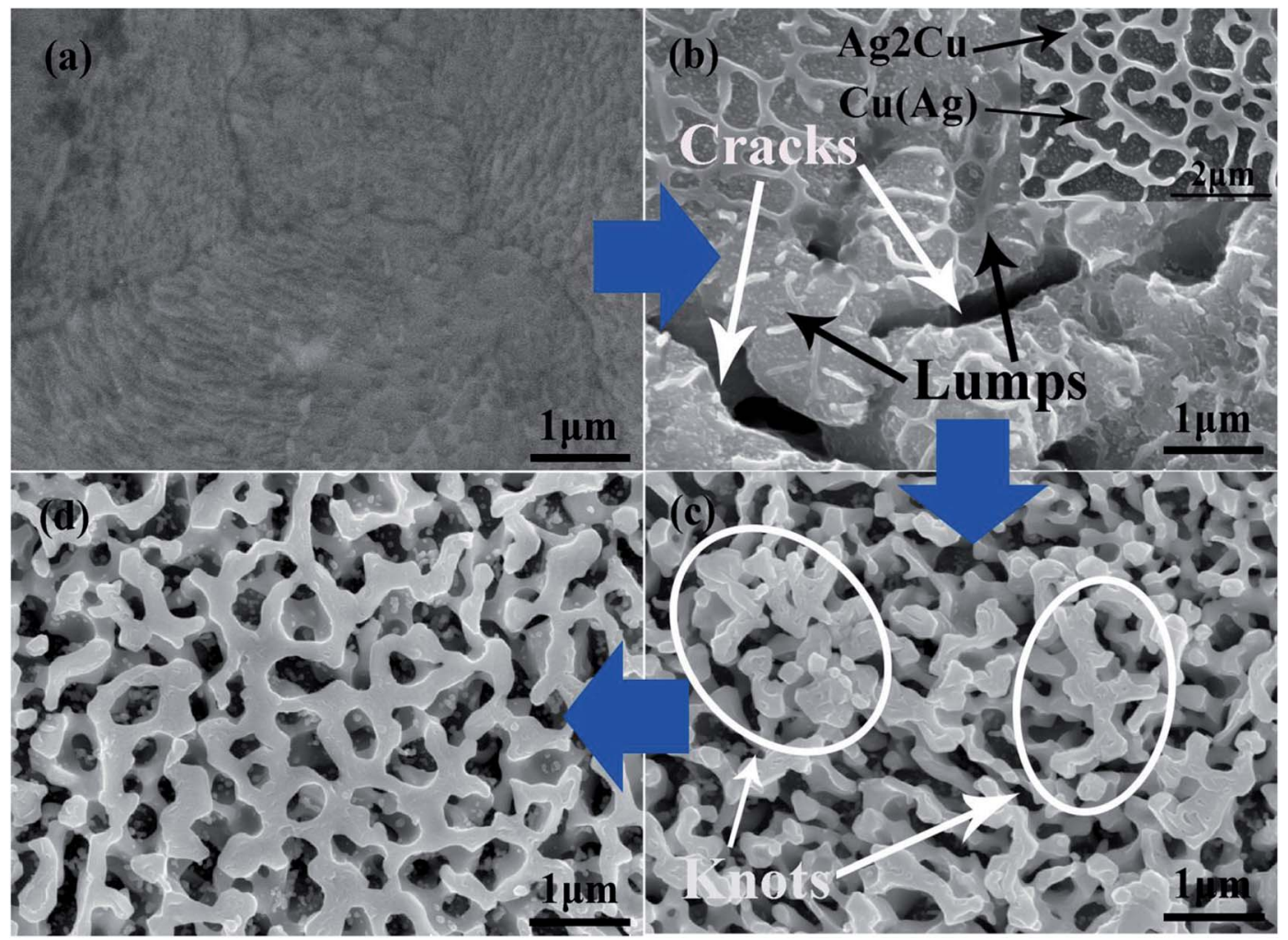

Fig. 6 Microstructures of $\mathrm{Ag}_{25} \mathrm{Cu}_{75}$ ribbons dealloyed under $\mathrm{UI}$ at $45^{\circ} \mathrm{C}$ in a 10 wt\% $\mathrm{HNO}_{3}$ aqueous solution for different durations: (a) 0 min, (b) $5 \mathrm{~min}$, (c) $10 \mathrm{~min}$, and (d) $20 \mathrm{~min}$; the inset in (b) is the image of microstructure at the initial stage. 
pore size of NPS dealloyed at $40 \mathrm{kHz}$, as shown in Fig. 4, were larger than those obtained at other frequencies.

\section{Formation mechanism of nanoporous Ag during dealloying with ultrasonic irradiation}

The formation mechanism of NPS may be somewhat distinctive with the application of UI. After the $\mathrm{Ag}_{25} \mathrm{Cu}_{75}$ alloy was immersed in the dealloying solution with ultrasonic treatment, $\mathrm{Cu}$ atoms on the surface will be leached away easily. The reaction of $\mathrm{Cu}$ in $\mathrm{HNO}_{3}$ aqueous solution could be described as follows:

$$
\begin{gathered}
\mathrm{HNO}_{3} \text { (hydrolyzed) } \rightarrow \mathrm{H}^{+}+\mathrm{NO}_{3}{ }^{-} \\
\mathrm{Cu}(\mathrm{Ag})+4 \mathrm{H}^{+}+2 \mathrm{NO}_{3}{ }^{-} \rightarrow \mathrm{Cu}^{2+}+2 \mathrm{NO}_{2} \uparrow+2 \mathrm{H}_{2} \mathrm{O}+\mathrm{Ag} \\
\mathrm{Ag}_{2} \mathrm{Cu}+4 \mathrm{H}^{+}+2 \mathrm{NO}_{3}{ }^{-} \rightarrow \mathrm{Cu}^{2+}+2 \mathrm{NO}_{2} \uparrow+2 \mathrm{H}_{2} \mathrm{O}+\mathrm{Ag}
\end{gathered}
$$

To fill the vacancies caused by the etching of the copper atoms, the $\mathrm{Ag}$ atoms on the interface between the alloy and dealloying solution moved and agglomerated into clusters by diffusion due to the effect of surface tension. ${ }^{32}$ With the assembly of the $\mathrm{Ag}$ atoms, ligaments were formed and coarsened gradually. Compared with free corrosion dealloying, the formation mechanism of NPS by dealloying $\mathrm{Ag}_{25} \mathrm{Cu}_{75}$ with UI developed in a new lump-forming-disintegrating manner, as described below.

Fig. 6a is the SEM image of $\mathrm{Ag}_{25} \mathrm{Cu}_{75}$ precursor alloy. When dealloying began, the $\mathrm{Cu}$ atoms exposed to the $\mathrm{HNO}_{3}$ solution would react actively with $\mathrm{H}^{+}$ions and then are transformed into free $\mathrm{Cu}^{2+}$ ions in the solution. At the moment, some walls and small particles can form on the alloy surface. According to the previous related reports, the wall structure was the $\mathrm{Ag}_{2} \mathrm{Cu}$ phase and the particle structure was $\mathrm{Cu}(\mathrm{Ag})$ phase. $\mathrm{And} \mathrm{Cu}(\mathrm{Ag})$ phase was dealloyed prior to the $\mathrm{Ag}_{2} \mathrm{Cu}$ phase. ${ }^{29,37,38}$ Moreover, the inset of Fig. $6 \mathrm{~b}$ is presented to illustrate the distributions of the $\mathrm{Cu}(\mathrm{Ag})$ solid solution and the $\mathrm{Ag}_{2} \mathrm{Cu}$ intermetallic compound in the $\mathrm{Ag}-\mathrm{Cu}$ alloy at the initial stage of dealloying. The structure of $\mathrm{Ag}_{2} \mathrm{Cu}$ and $\mathrm{Cu}(\mathrm{Ag})$ are both marked using black arrows. Influenced by ultrasonic condition, many cracks and lumps can then be formed on the surface layer of the sample (Fig. 6b). However, many residual $\mathrm{Ag}_{2} \mathrm{Cu}$ walls were still on the surface of

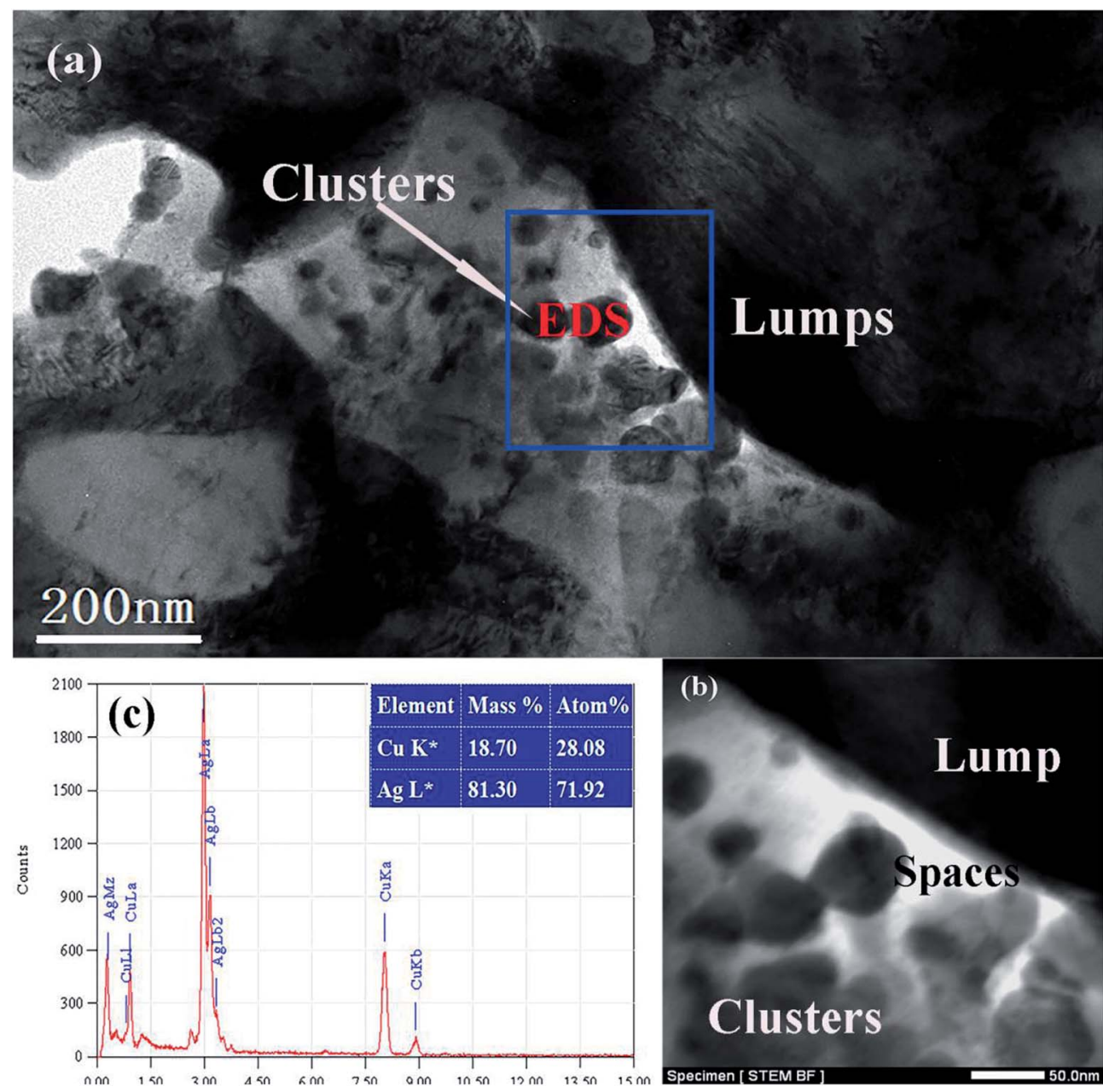

Fig. 7 (a) TEM images of NPS produced by dealloying $\mathrm{Ag}_{25} \mathrm{Cu}_{75}$ within $\mathrm{Ul}$ at the frequency of $40 \mathrm{KHz}$ in 10 wt\% $\mathrm{HNO}_{3}$ aqueous solution for 5 min. (b) Is the EDS pattern marked in (a). (c) Is the part enlarged bright-field scan transmission electron microscope (STEM BF) image of (a) which is remarked by a blue rectangle. 
the lumps as illustrated in Fig. 6b. Their sizes measuring to be $45 \pm 15 \mathrm{~nm}$ are very small.

For further characterizing the lump structure, TEM images of the $\mathrm{Ag}_{25} \mathrm{Cu}_{75}$ alloy sample dealloyed with UI at the frequency of $40 \mathrm{kHz}$ for $5 \mathrm{~min}$ are represented in Fig. 7a. Some large plates and thin particles corresponding to lumps and clusters respectively can be observed clearly. The EDS pattern (Fig. 7b) confirmed that the particles were actually the Ag-rich clusters. There are a lot of spaces appearing between the plate and particles. This demonstrates the appearance of cracks at the
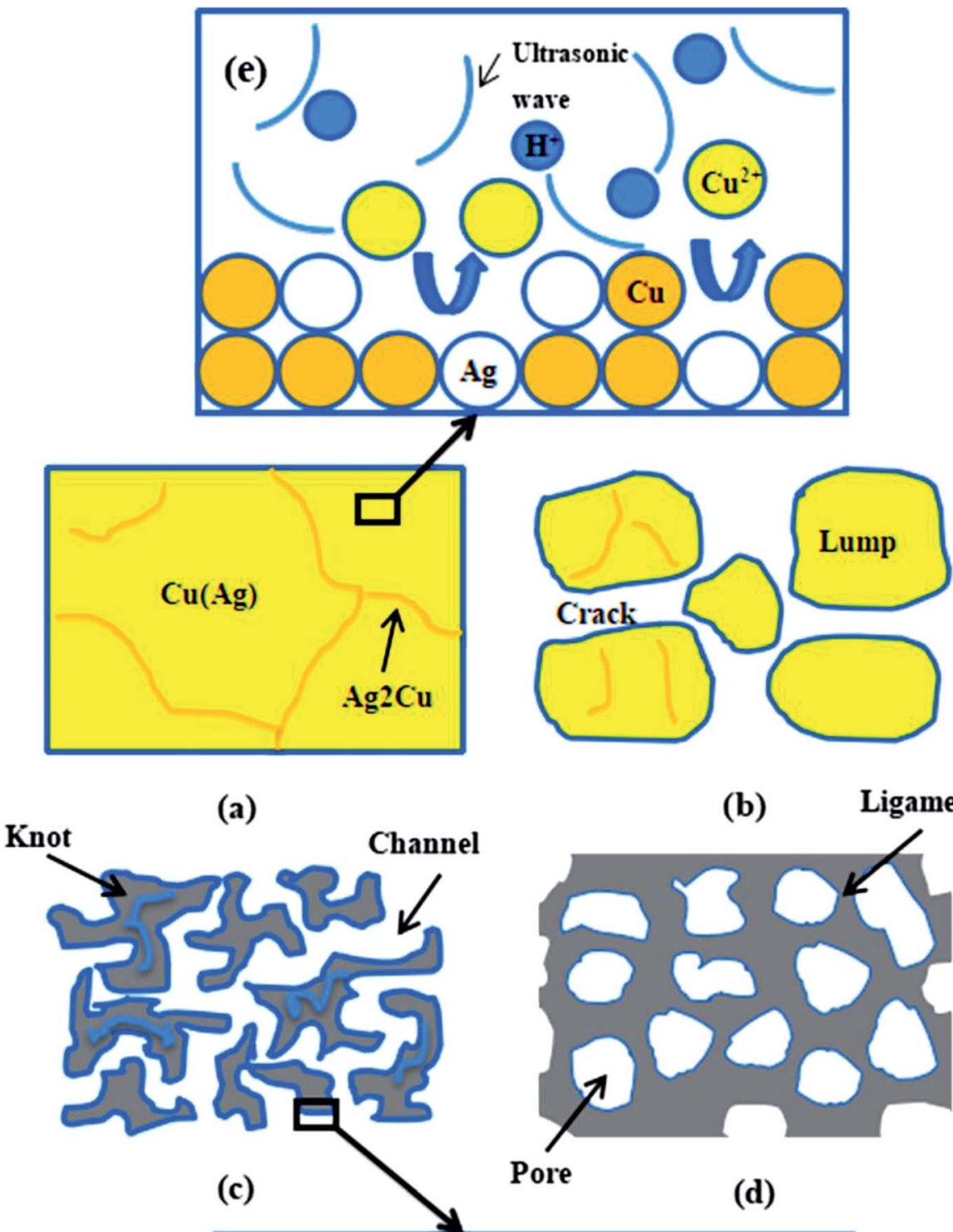

(b)

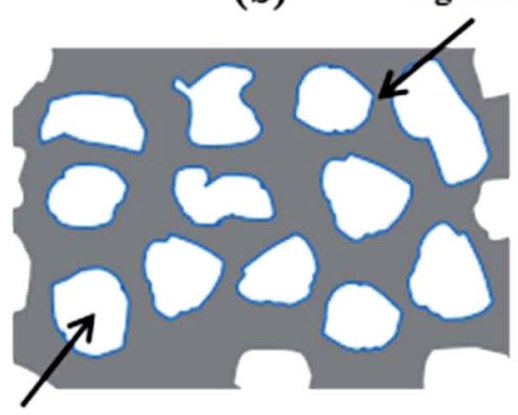

Pore

(d)

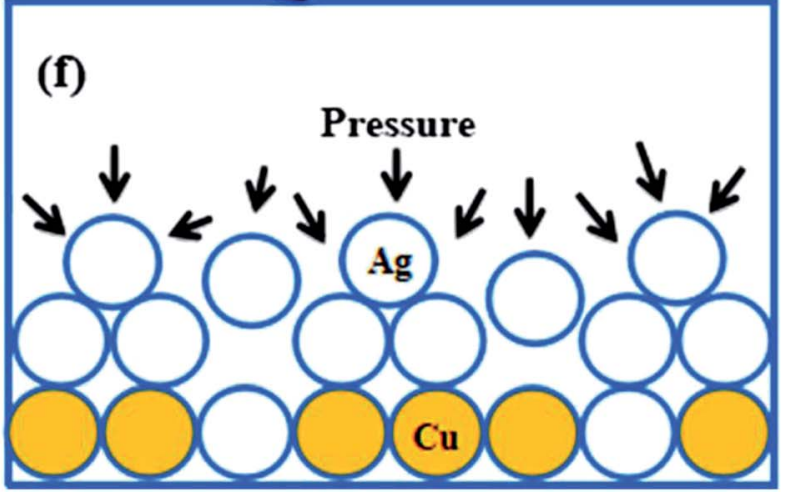

Fig. 8 (a)-(d) Schematic diagram of NPS formation process when $\mathrm{Ag}_{25} \mathrm{Cu}_{75}$ Alloy is dealloyed in a Ul; (e) and (f) are the schematic diagrams of reaction interface at period of (a) corrosion and (c) diffusion. 
beginning of dealloying. The formation of vacancies may support the hypothesis that high-intensity ultrasonic irradiation could accelerate the reaction process between $\mathrm{Cu}$ and $\mathrm{HNO}_{3}$. Fig. 7c is the bright-field scanning transmission electron microscopy (STEM BF) image. It shows an enlarged view of a part of Fig. 8a which was marked by a blue rectangle and represent the distributions of lumps, clusters and cracks clearly. Distinctly, the lumps (corresponding to plates) and cracks (corresponding to vacancies) have formed at the initial stage of dealloying and the clusters moved and aggregated on the surface of the lumps.

As the dealloying continued, more $\mathrm{Cu}$ atoms were leached away leading to the decrease of the $\mathrm{Cu}$ content in alloy. The number and the size of the pores increased correspondingly. Then the lumps shrank and disintegrated gradually. Due to the further removal of $\mathrm{Cu}$ atoms, more $\mathrm{Ag}$ atoms exposed to solution moved and assembled to form the ligament. As a result, many large knots composed of ligaments appeared which was marked by the white circles in Fig. 6c. It is obvious that they evolved from the large lumps to the thinner knots. Subsequently, the coarsening of the ligaments proceeded and the knots vanished gradually until an ultra-homogeneous nanoporous structure ultimately formed (Fig. 6d). The whole dealloying process of $\mathrm{Ag}_{25} \mathrm{Cu}_{75}$ alloy in an ultrasonic environment can be illustrated in details by a schematic diagram (Fig. 8a-d).

As previously reported, the application of ultrasonic fields into the solution could give rise to phenomena such as cavitation and acoustic streaming which could lead to the effects of ultrasonic stirring and degassing. ${ }^{39}$ We assumed the ultrasonic irradiation could generate high-intensity shock waves to effectively accelerate the reaction between $\mathrm{Cu}$ and the $\mathrm{HNO}_{3}$ solution. The stirring and shocking effect could generate waves in the medium solution as shown in Fig. 8e. That would greatly increase the chance of collision and contact among the atoms which were involved in the reaction system, such as the reaction between $\mathrm{H}^{+}$ions hydrolyzed in the solution and $\mathrm{Cu}$ atoms crystalized in the alloy. Hence $\mathrm{Cu}$ atoms were more inclined to be separated from the alloy and turned into $\mathrm{Cu}^{2+}$ compared with those dealloyed through free corrosion. As a result, cracks and lumps appeared at the initial stage of dealloying process with ultrasonic irradiation.

In addition, the ultrasonic vibration could facilitate the coarsening of $\mathrm{Ag}$ ligament. The acoustic streaming effects originating from ultrasonic vibration may affect the diffusion of $\mathrm{Ag}$ atoms. As reported, the streaming was eventually related to the pressure present in the dealloying solution and the pressure acting on diffusing atoms could be described by: ${ }^{\mathbf{4 0}}$

$$
P_{\mathrm{a}}=v \rho c=\rho c A_{0} \omega \cos \left(\omega t-\omega \frac{x}{c}\right) .
$$

Obviously, the maximum value of the pressure could approximately be simplified into:

$$
P_{\max }=\nu \rho c=\rho c A_{0} \omega,
$$

where $A_{0}$ is the amplitude $(\mu \mathrm{m}), \omega$ is the frequency $(\mathrm{Hz})$ of the ultrasonic field, $x / c$ is the phase factor, $\rho$ is the density of the dealloying solution $\left(\mathrm{g} \mathrm{cm}^{-3}\right)$ and $c$ is the speed of sound in the $\mathrm{HNO}_{3}$ aqueous solution $\left(\mathrm{m} \mathrm{s}^{-1}\right)$. In this system, $\rho \approx$ $1.06 \mathrm{~g} \mathrm{~cm}^{-3}, c \approx 1.51 \times 10^{3} \mathrm{~m} \mathrm{~s}^{-1}, A_{01}=3.3 \mu \mathrm{m}$ for $\omega_{1}=2.8 \times$ $10^{4} \mathrm{~Hz}$, and $A_{02}=4.2 \mu \mathrm{m}$ for $\omega_{2}=4.0 \times 10^{4} \mathrm{~Hz}$. Therefore, $P_{\max 1}$ and $P_{\max 2}$ are estimated to be $0.15 \mathrm{MPa}$ and $0.27 \mathrm{MPa}$, approximately equal to 1.5 and 3 atmospheres, respectively.

When the alloy ribbon was immersed in the dealloying solution with ultrasonic vibration, the whole surface of alloy ribbon was under the pressure from all directions. The schematic diagram of reaction interface when $\mathrm{Ag}_{25} \mathrm{Cu}_{75}$ Alloy is dealloyed with UI during the period of diffusion is presented in Fig. 8f. Since Ag atoms at the surface of alloy are all under the pressure from multi-direction, the $\mathrm{Ag}$ atoms (or particles) become more aggressive during diffusion process. The movement rate of $\mathrm{Ag}$ atoms was accelerated and the diffusion was forced intensely. As a result, an extremely homogeneous microstructure of the nanoporous $\mathrm{Ag}$ with a coarsened ligament-pore distribution was obtained. Moreover, the microstructure of the ultrasonically treated sample was much more homogeneous than that of the free corrosion samples.

\section{Conclusions}

Effects of ultrasonic irradiation (UI) on the diffusion and microstructure of NPS were analyzed. The following conclusions were drawn: the formation mechanism of NPS dealloying with UI was different from that for NPS obtained by free corrosion. The NPS evolved depending on a lump formingdisintegrating mechanism. Ultrasound has an extremely strong effect on the microstructure of NPS. On one hand, the stirring produced by ultrasonic vibration could promote the reaction between $\mathrm{Cu}$ and $\mathrm{HNO}_{3}$ aqueous solution. On the other hand, ultrasonic vibration could facilitate the diffusion of $\mathrm{Ag}$ atoms by the induced solution pressure when the coarsening rate of ligament was increased significantly during dealloying with UI. Dealloying treated with ultrasonic irradiation could generate an extremely homogeneous microstructure with much coarser ligaments compared with those dealloyed by free corrosion.

\section{Conflicts of interest}

There are no conflicts to declare.

\section{Acknowledgements}

The authors gratefully acknowledge the sponsorship from National Natural Science Foundation of China, under the project no. 51574147, Liaoning Provincial Natural Science Foundation, under the project no. 201602474.

\section{References}

1 A. Wittstock, V. Zielasek and J. Biener, Science, 2010, 327, 319-322. 
2 N. Yu, L. Jiang and H. Hou, JOM, 2017, 69(6), 1027-1033.

3 H. J. Jin, X. L. Wang and S. Parida, Nano Lett., 2010, 10, 187194.

4 Y. C. Liu, J. C. Huang and X. Wang, RSC Adv., 2018, 8, 1307513082.

5 N. Yu, T. Wang, C. Nie, L. Sun, J. Li and H. Geng, JOM, 2016, 68(1), 391-396.

6 G. J. Li, X. P. Song and F. F. Lu, J. Mater. Res., 2012, 27(12), 1612-1620.

7 Y. Zhao, X. Wang and J. C. Huang, Mater. Lett., 2016, 183, 165-169.

8 T. A. Rebbecchi and Y. Chen, J. Mater. Res., 2017, 33, 1-14.

9 R. W. Zhang, X. Wang and Z. C. Zhang, RSC Adv., 2018, 8, 9462-9470.

10 W. Liu, L. Chen and J. Yan, Corros. Sci., 2015, 94, 114-121.

11 R. Morrish, K. Dorame and A. J. Muscat, Scr. Mater., 2011, 64, 856-859.

12 T. Krekeler, V. S. Anastasia and M. Graf, Mater. Res. Lett., 2017, 5, 1-8.

13 H. B. Lu, Y. Li and F. H. Wang, Scr. Mater., 2007, 56(2), 165168.

14 Z. Dan, F. Qin and S. I. Yamaura, J. Alloys Compd., 2013, 581, 567-572.

15 M. Hakamada, H. Nakano and T. Furukawa, Phys. Chem. Chem. Phys., 2011, 13(26), 12277-12284.

16 L. H. Qian and M. W. Chen, Appl. Phys. Lett., 2007, 91, 597605.

17 Z. Zhang, Y. Wang and Z. Qi, J. Phys. Chem. C, 2009, 113, 12629-12636.

18 H. Rösner, S. Parida and D. Kramer, Adv. Eng. Mater., 2010, 9, 535-605.

19 X. Wang, Z. Qi and C. Zhao, J. Phys. Chem. C, 2009, 113, 13139-13150.

20 L. Y. Chen, J. S. Yu and T. Fujita, Adv. Funct. Mater., 2010, 19, 1221-1226.
21 W. C. Li and T. J. Balk, Scr. Mater., 2010, 62, 167-169.

22 Y. Y. Zhao, D. Estévez and C. Chang, Mater. Lett., 2015, 144, 138-141.

23 T. Song, Y. Gao, Z. Zhang and Q. Zhai, CrystEngComm, 2012, 14, 3694-3701.

24 Z. Lu, C. Li and J. Han, Nat. Commun., 2018, 9(1), 276-283.

25 H. B. Xu, T. T. Meek and Q. Y. Han, Mater. Lett., 2007, 61, 1246-1250.

26 Z. W. Xu, J. C. Yan and W. Chen, Mater. Lett., 2008, 62, 26152618.

27 Z. W. Liu, Q. Y. Han and J. G. Li, Composites Part B: Engineering, 2011, 42, 2080-2084.

28 Z. W. Liu, M. Rakita and Q. Han, Metall. Mater. Trans. A, 2012, 43, 2116-2124.

29 F. Chen, X. Chen and L. J. Zou, Mater. Sci. Eng., A, 2016, 660, 241-250.

30 H. J. Qiu, L. Peng and X. Li, Corros. Sci., 2015, 92, 16-31.

31 N. Hirai, H. Tanaka and S. Hara, Appl. Surf. Sci., 1998, 130, 506-511.

32 M. S. Kim and H. Nishikawa, J. Mater. Sci., 2013, 48, 56455652.

33 Y. Sun and T. J. Balk, Metall. Mater. Trans. A, 2008, 39, 26562665.

34 J. Erlebacher, M. J. Aziz and A. Karma, Nature, 2001, 410, 450-453.

35 J. Erlebacher, J. Electrochem. Soc., 2004, 151, C614-C626.

36 Z. Zhang, Y. Wang and Y. Wang, Scr. Mater., 2010, 62, 137140.

37 E. Detsi, Z. Vuković and S. Punzhin, CrystEngComm, 2012, 14, 5402-5406.

38 T. T. Song, Y. L. Gao and Z. H. Zhang, Corros. Sci., 2013, 68, 256-262.

39 Z. W. Liu, X. M. Wang and Q. Y. Han, Metall. Mater. Trans. A, 2014, 45(2), 543-546.

40 Z. Liu, Q. Han and J. Li, Powder Technol., 2013, 247, 55-59. 